\title{
Correlation between Electrochemical Impedance Spectroscopy and Structural Properties of Amorphous Tunisian Metanacrite Synthetic Material
}

\author{
Nouha Jaafar, Hafsia Ben Rhaiem, and Abdessalem Ben Haj Amara \\ Department of Physics, UR05/13-01: Laboratory of Physics of Lamellar Hybrid Materials and Nanomaterials, \\ Faculty of Science of Bizerte, 7021 Zarzouna, Tunisia
}

Correspondence should be addressed to Nouha Jaafar; nouhajaafar@yahoo.fr

Received 29 July 2014; Accepted 28 October 2014; Published 17 November 2014

Academic Editor: Somchai Thongtem

Copyright (C) 2014 Nouha Jaafar et al. This is an open access article distributed under the Creative Commons Attribution License, which permits unrestricted use, distribution, and reproduction in any medium, provided the original work is properly cited.

\begin{abstract}
In the present work, we report the structural and electrochemical properties of metanacrite. Metanacrite is a synthetic material originated by heating $\left(550^{\circ} \mathrm{C}\right)$ of a clay mineral (Tunisian nacrite) belonging to the kaolin group. The structure of the amorphous synthetic product was corroborated by X-ray diffraction (disappearing of nacrite peaks) and infrared spectroscopy (disappearing of $\mathrm{Al}-\mathrm{OH}$ and water bands). The decomposition of the silicate framework was confirmed by transmission electron microscope (TEM). The obtained metanacrite synthetic material was also examined by electrochemical impedance spectroscopy (EIS). Accordingly, the electronic conduction is followed by the correlated barrier hopping (C.B.H.) model. Therefore, by combining ac and dc electrical conductivity, a semiconductor behavior is evidenced. The dependence of the dielectric constant $\left(\varepsilon^{\prime}\right)$ and dielectric loss $\left(\varepsilon^{\prime \prime}\right)$ on both temperature and frequency is also discussed.
\end{abstract}

\section{Introduction}

Clay materials are the most common components of all sediments and soils in the Earth's crust. Most of the researches and developments in clay materials come from technological needs for its low cost, easy availability, nontoxicity, bulk properties, and its surface chemical properties [1].

Among a wide variety of clay resources, kaolin is considered as one of the most promising candidates due to its engineering and industrial applications in several sectors such as porcelain, pottery manufacturing, ceramics, nuclear waste treatment, paper manufacturing, and pharmaceutical and cosmetic industries [2-4]. Kaolin, with the chemical formula $\mathrm{Al}_{2} \mathrm{Si}_{2} \mathrm{O}_{5}(\mathrm{OH})_{4}$, is a dioctahedral clay mineral of 1:1 layer type. One side of the layer is gibbsite-like with aluminium atoms octahedrally coordinated to corner oxygen atoms and hydroxyl groups. The other side of the layer constitutes a silica-like structure in which the silicon atoms are tetrahedrally coordinated to oxygen atoms. The adjacent layers are linked via hydrogen bonds $(\mathrm{O}-\mathrm{H} \cdots \mathrm{O})$ involving aluminol $(\mathrm{Al}-\mathrm{OH})$ and siloxane $(\mathrm{Si}-\mathrm{O})$ groups. The kaolin group is divided into three polytypes (i.e., nacrite, kaolinite, and dickite) in addition to halloysite, their hydrated analogue [5].

Recently, several studies focused on the physicochemical characteristics of metakaolin (MK) materials derived from dehydroxylation of kaolin at $823 \mathrm{~K}$. This phenomenon is accompanied by loss of water and decomposition into a disordered metastate [6], which undergoes massive structural changes of the octahedral layer: aluminium changes its coordination from six to four and five [7-9]. This metastable state yields highly activated aluminosilicate and environmentally friendly synthetic material used as follows.

(i) An inexpensive adsorbent for the removal and recovery of uranium, in particular for the treatment of wastewater [10].

(ii) A relatively new material in several research projects concerning cement and construction materials [1113]: for example, in the concrete industry, MK is very effective in increasing strength, reducing sulphate attack, and improving air-void network; high strength 
concrete (HSC) with metakaolin as admixtures offers then many advantages, so it can be used for (a) dams, (b) bridges, (c) water retaining structures, (d) high rise buildings, (e) off shore structures, (f) industrial flooring, (g) warehouses, (h) container depots, (i) roads, (j) lining, (k) mass concreting, (l) aqueducts, (m) nuclear power stations, and (n) structural members where cross section is required to be small and so forth [14].

(iii) A good pozzolanic source suitable for the preparation of performed geopolymers: these geopolymers are known as high ionic conductors used for all solidstate batteries, electrochemical sensors, and so forth [15].

In the present study, a similar calcination process is adopted to a Tunisian "nacrite" sample in order to elaborate a novel metastable synthetic material, commonly named "metanacrite."

Nacrite belongs to the kaolin polymorph and was previously described in the works of Ben Haj Amara et al. [1620] and recently functionalized in the work of Jaafar et al. [21]. Bailey [5] described nacrite by a $2 \mathrm{M}$ stacking mode which crystallized in the monoclinic lattice with a Cc space group. The structural parameters of nacrite are $a=8.906 \AA$, $b=5.146 \AA, c=15.669 \AA$, and $\beta=113.58^{\circ}$ with a main basal distance $d_{002}=c \sin \beta / 2=7.18 \AA$ [17-19].

The dehydroxylation process may be presented by the following simple equation:

$$
\underset{\text { nacrite }}{\mathrm{Al}_{2} \mathrm{O}_{3} \cdot 2 \mathrm{SiO}_{2} \cdot 2 \mathrm{H}_{2} \mathrm{O}} \longrightarrow \underset{\text { metanacrite }}{\mathrm{Al}_{2} \mathrm{O}_{3} \cdot 2 \mathrm{SiO}_{2}}+\begin{gathered}
2 \mathrm{H}_{2} \mathrm{O} \\
\text { water }
\end{gathered}
$$

The obtained metanacrite was then analyzed via X-ray diffraction (XRD), infrared spectroscopy (IR), and transmission electron microscopy (TEM) in order to highlight the structural features of the calcined material at different scales. This allows achievement of better applicability of Tunisian metanacrite, as a new synthetic source of pozzolan, for producing composite building materials.

So far, no study has been reported on the electrical and dielectric properties of Tunisian metanacrite. This is the main point addressed in this paper. The study of the electrochemical characteristic of metanacrite is based on the structural analysis in order to correlate the material response to defects and disorder ratio induced by dehydroxylation of nacrite.

\section{Experimental Procedure}

Nacrite raw material used in this work was collected from the mine of Jbel Slata located in the region of Kef in North Tunisia [16]. The sample shows large particles and minor impurities and represents an available raw material for the synthesis of metanacrite. The sample of about $20 \mathrm{~g}$ was heat treated in the laboratory furnace. The optimal calcination parameters, for which complete dehydroxylation of the material was achieved, are temperature of $823 \mathrm{~K}$ and heating time of $120 \mathrm{~min}$. The conversion of the nacrite to metanacrite was followed by XRD, IR, TEM, and EDXS.
The qualitative XRD investigation consisted in a global description based on the profile geometry (peaks symmetry and/or asymmetry, shape, angular width at half height, $d_{00 l}$ basal spacing values. .., etc.) in order to acquire a preliminary idea about the analyzed sample. The X-ray diffraction (XRD) patterns were obtained by reflection setting with a D8 Bruker installation monitored by the EVA-version Diffrac plus software (Bruker AXS GmbH, Karlsruhe, Germany) and using $\mathrm{CuK} \alpha_{1}$ radiation $(\lambda=1.54186 \AA)$. Usual scanning parameters were $0.02^{\circ} 2 \theta$ as step size and $6 \mathrm{~s}$ as counting time per step over the angular range $2-50^{\circ} 2 \theta$.

IR spectroscopy is used as a valuable tool to determine the frequencies evolution of metanacrite bands. IR spectra are recorded at room temperature using a Thermo Scientific Nicolet IR 200 FT-IR with ATR Spectrometer, equipped with a diamond crystal operating in the frequency range 4000$400 \mathrm{~cm}^{-1}$.

The morphology, size, and composition of the synthesized sample were characterized via local chemical microanalysis performed using energy dispersive X-ray spectroscopy (EDXS) coupled to the transmission electron microscope (TEM) (FEI Tecnai G2) operating at $200 \mathrm{kV}$.

The sample preparation process and the microstructure of the resultant amorphous synthetic material play a major role in the transport properties. For this purpose, we carried out electrochemical impedance spectroscopy (EIS) using a Hewlett-Packard (HP) 4192 analyzer. The impedance measurements were taken in an open circuit with a signal amplitude of $50 \mathrm{mV}$ and a frequency band ranging from $10 \mathrm{~Hz}$ up to $13 \mathrm{MHz}$ at different temperatures. The examined sample is pressed into pellet using a hydraulic press. To ensure good electrical contact between the sample and the electrical junctions, the pellet was sandwiched between two platinum electrodes to form a symmetrical cell. The cell was placed into a programmable oven coupled with a temperature controller. The resulting data were fitted using the equivalent circuit of the Zview software.

\section{Results and Discussion}

The experimental XRD patterns of both nacrite and metanacrite are reported in Figures 1(a) and 1(b), respectively. Results show a broad characteristic reflection extending from approximately 17 to $39^{\circ} 2 \theta$ attributed to the overlapping of the $00 l$ reflections of the well crystallized natural nacrite [16-20]. The XRD analysis represents then the amorphous structure of the obtained metanacrite synthetic phase.

By comparing the IR spectra of metanacrite and nacrite recorded in Figure 1(c), it is possible to follow the modifications of the stretching and deformation vibrations obtained after heating nacrite above $823 \mathrm{~K}$ : they shift from their positions in the spectrum of untreated nacrite, and their shapes change.

Indeed, at high frequencies, it should be mentioned that no bands were detected in the infrared spectrum of metanacrite, indicating the disappearance of the $\mathrm{OH}$ lattice stretching band since it is located in the envelope of water band corresponding to natural nacrite at 3714 and $3647 \mathrm{~cm}^{-1}[16-$ 20]. Figure $1(\mathrm{c})$ reveals that, at low frequencies, the $\mathrm{Si}-\mathrm{O}$ 


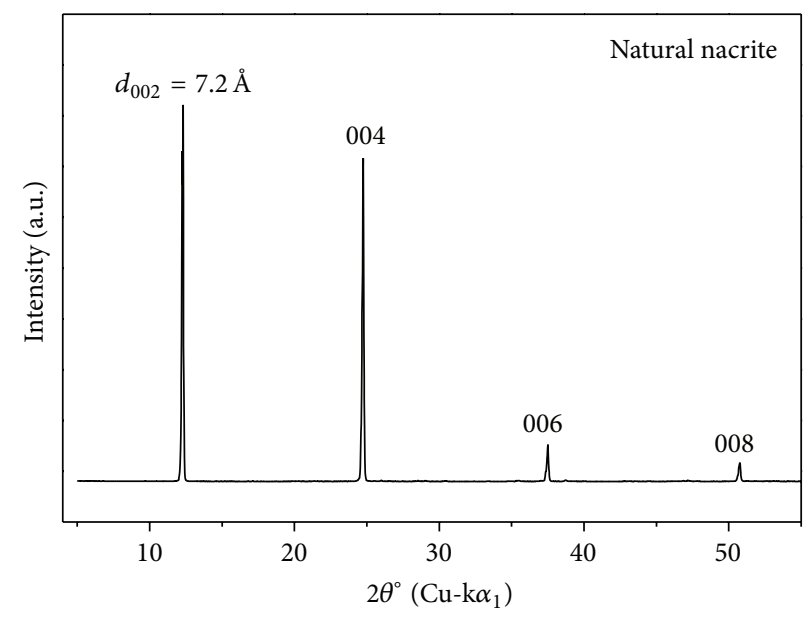

(a)

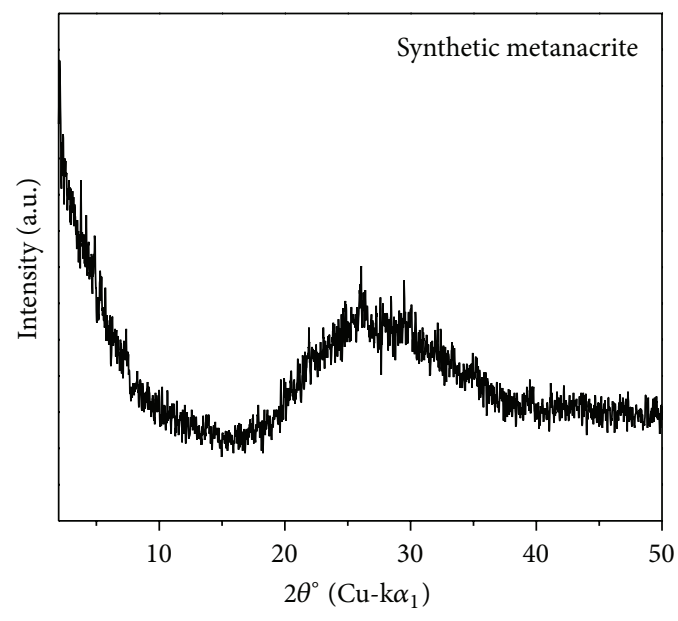

(b)

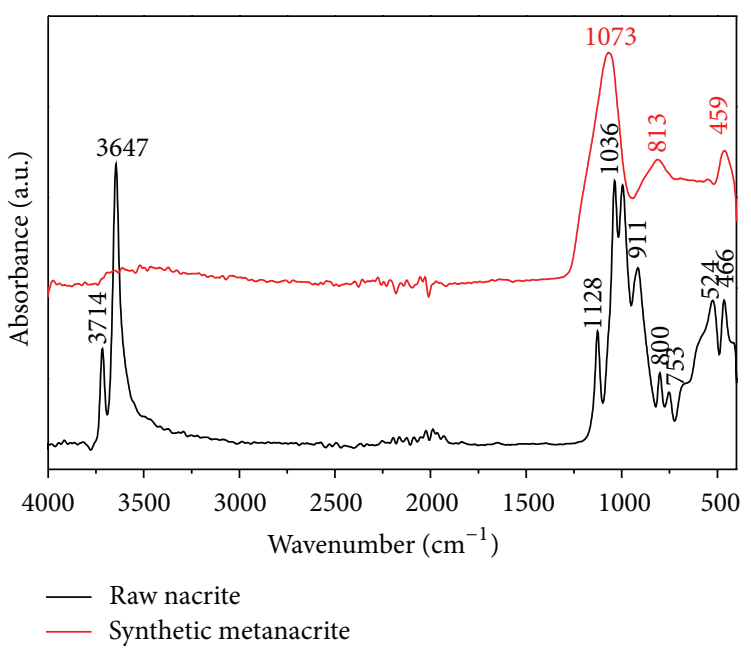

(c)

Figure 1: (a) Experimental X-ray pattern of nacrite raw-clay material. (b) Experimental X-ray pattern of metanacrite synthetic material. (c) Infrared spectra in the $4000-400 \mathrm{~cm}^{-1}$ region for nacrite and metanacrite samples.

stretching vibrations $\nu(\mathrm{Si}-\mathrm{O})$ located at $1073 \mathrm{~cm}^{-1}$ and the $\mathrm{Si}-$ O deformation vibrations located at $459 \mathrm{~cm}^{-1}$ are commonly present with a slight change in their shape and intensity, while the $\mathrm{Al}-\mathrm{O}$ deformation vibrations are shifted to high frequencies from 524 to $813 \mathrm{~cm}^{-1}$ and the Al-OH deformation vibrations placed at 753,800 , and $911 \mathrm{~cm}^{-1}$ in the spectrum of nacrite are omitted in the spectrum of metanacrite.

All these changes in the infrared spectrum between metanacrite and nacrite imply that the starting aluminosilicate loses water during calcinations. The layered structure is then destroyed and transformed into a disordered metastate characterized by major changes in the octahedral sheet with minor changes in the tetrahedral sheet. In other words, metanacrite phase possesses amorphous structure very different from the nacrite matrix.

Figure 2(a) provides the TEM observations micrographs of Tunisian metanacrite. At first glance, the studied sample exhibits a disordered granular structure with various shapes and sizes. We note the presence of defects, mostly dislocations, which are generated by the distortion around the particle. The contributions of defects, grain size, distribution, and morphology confirm that the amorphous behavior dominates the whole structural composition of metanacrite synthetic material.

Such defects seem to be produced during the heating of the starting nacrite clay material and play an important role in the second part of this paper. The larger the number of defects and disorder, the higher the mobility of the free charge carriers, which results in an improvement of the conduction behavior.

In order to obtain more detailed information about the microstructure and the chemical composition of metanacrite, we performed TEM coupled with EDXS analysis. The obtained spectra (Figure 2(b)) show the presence of Si and Al atoms with a major proportion, constituting the fundamental elements of the metanacrite phase, with a minor contribution of $\mathrm{Fe}$ and $\mathrm{Cu}$ atoms corresponding to the presence of a trace amount of impurities in the metanacrite material. However, 

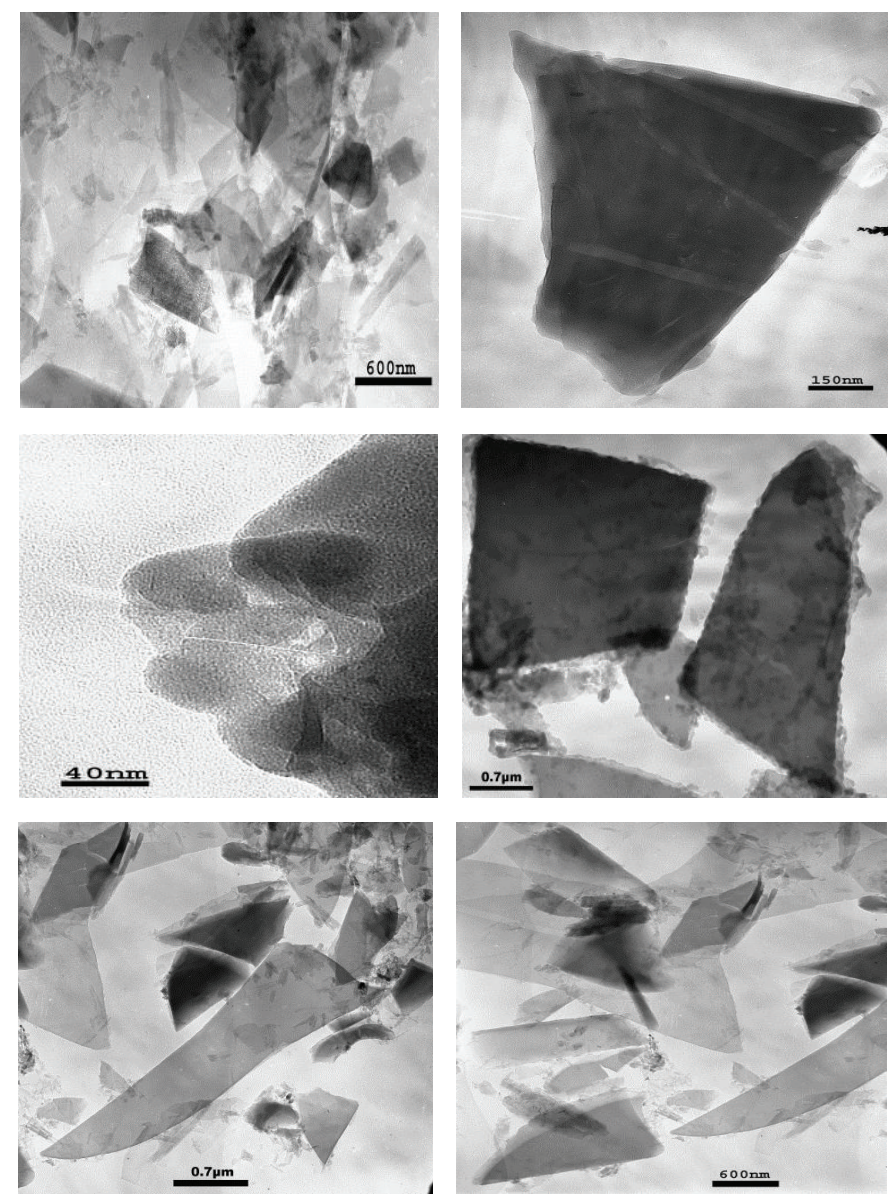

(a)
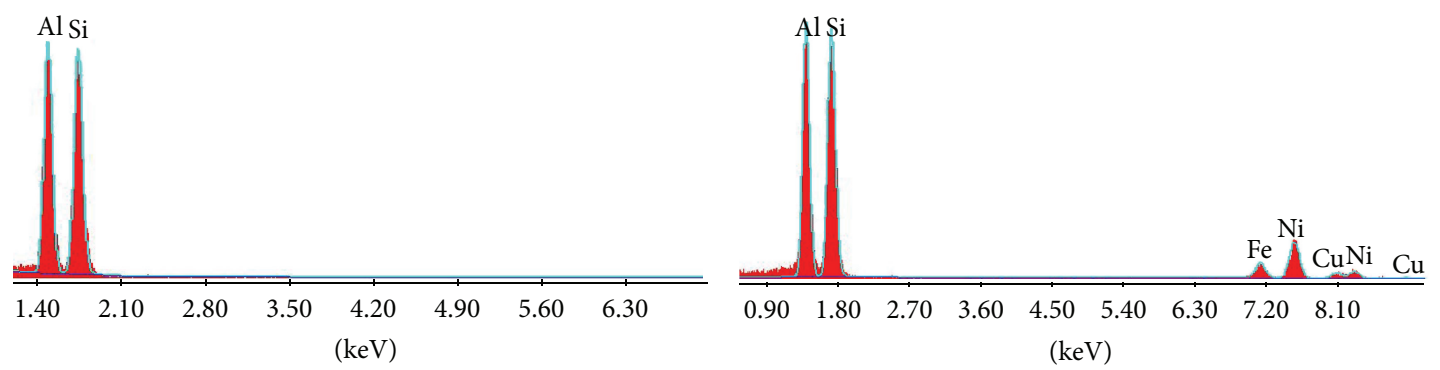

(b)

FIGURE 2: (a) TEM micrographs of metanacrite synthetic material. (b) EDXS spectra of metanacrite.

the presence of $\mathrm{Ni}$ atoms belongs to the membrane on which the sample is placed.

The preliminary physicochemical analysis of metanacrite reveals that the sample is mainly in high amorphous aluminosilicate phase with a disordered polymerized silicon/aluminum framework.

In this section, we will discover the influence of the heat treatment of metanacrite from room temperature to $873 \mathrm{~K}$ on the enhancement of the electrical conductivity and the dielectric permittivity.

Accordingly, the complex impedance plots of metanacrite in the temperature range $298-873 \mathrm{~K}$ are displayed in Figure 3(a).
The Nyquist plots describe the transport properties which are strongly affected by the microstructure. From Figure 3(a), two domains are identified: the first one is observed at low temperature $(298 \mathrm{~K}-673 \mathrm{~K})$ describing the insulator behavior and the second one is detected at high temperature (673$873 \mathrm{~K}$ ) for which a significant increase in conductivity is observed. The increase of the electrical conductivity may be attributed to an increase of the disorder degree as well as defects density in the sample. The electric response of the sample was fitted in the frequency domain by a simple equivalent circuit involving constant phase element $R_{s}\left(\mathrm{CPE}, R_{p}\right)$ 


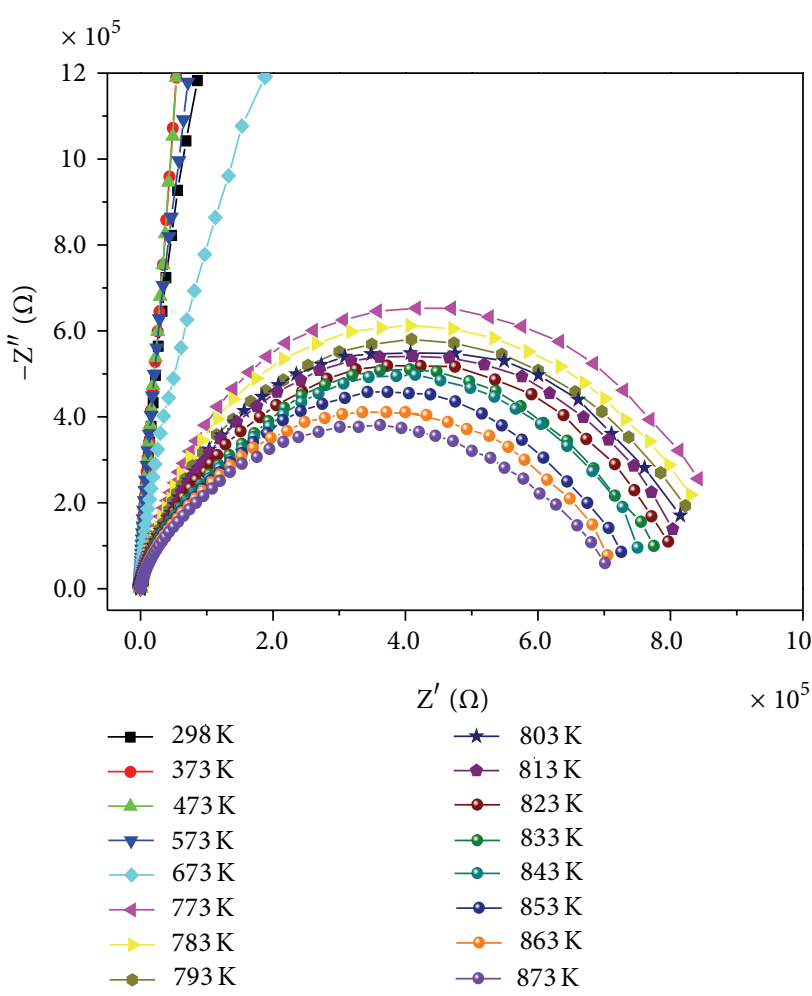

(a)

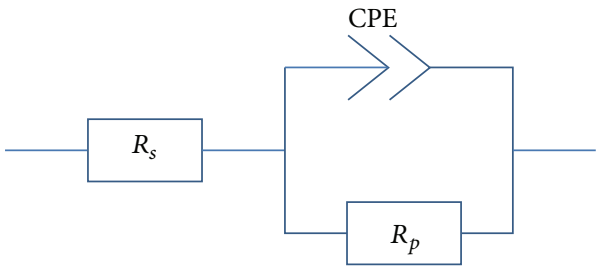

(b)

FIGURE 3: (a) Nyquist diagram of metanacrite at the temperature range from 298 to $873 \mathrm{~K}$. (b) The equivalent circuit of metanacrite compound. $R_{s}$ and $R_{p}$ represent electric resistance elements. CPE represent constant phase element: $1 / Z_{\mathrm{CPE}}=Y_{0}(j \omega)^{\beta}$, where $Y_{0}$ is the admittance $(1 /|Z|)$ at $\omega=1 \mathrm{rad} / \mathrm{s}$ and $\beta$ a value between 0 and 1 .

(Figure 3(b)), where $R_{s}$ and $R_{p}$ represent series and parallel connection of grain resistance, respectively.

In general, at fixed temperature and over a wide range of frequencies, the total conductivity can be expressed as [22]

$$
\sigma_{t}=\sigma_{\mathrm{dc}}+A \omega^{s}=\sigma_{\mathrm{dc}}+\sigma_{\mathrm{ac}},
$$

where $\sigma_{\mathrm{ac}}$ is the ac conductivity, $\sigma_{\mathrm{dc}}$ is the bulk conductivity, $A$ is a temperature dependent parameter which determines the strength of polarisability, and the exponent $s$ represents the degree of interaction between mobile charge carriers of the specimen.

Using the empirical relation given by (3) $\sigma_{\mathrm{ac}}$ is calculated:

$$
\sigma_{\mathrm{ac}}=\frac{g}{R},
$$

where $g$ represents the geometric factor given by

$$
g=\frac{d}{S}=\frac{d}{\left(\pi r^{2}\right)}
$$

where $d$ corresponds to the thickness of the pellet, $r$ is the radius of the pellet, $S$ is the area of the pellet, and $R$ is the resistance.

The values of the frequency exponent $s$ as determined are presented in Figure 4 as a function of temperature. As it can be seen, the frequency exponent values decrease with temperature from 0.69 to 0.36 .

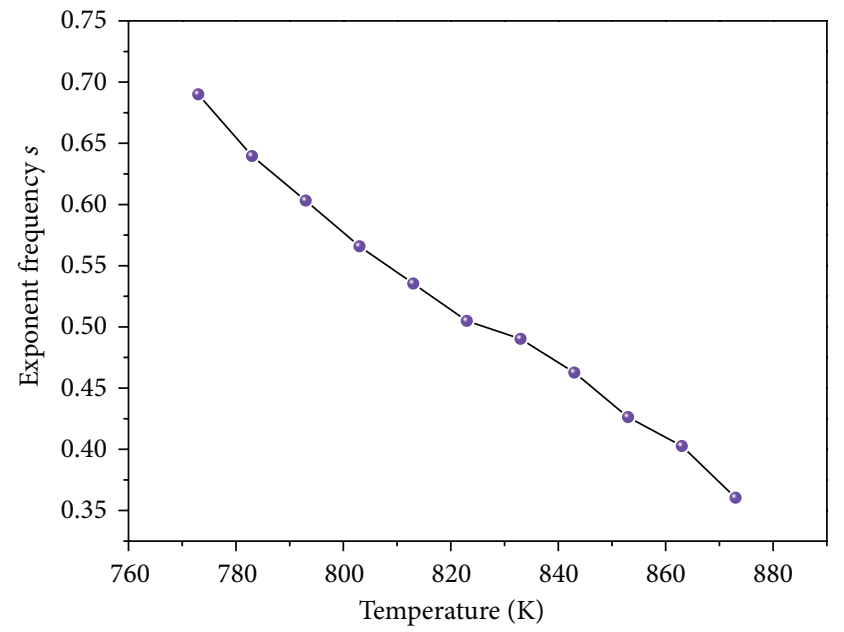

Figure 4: Temperature dependence of frequency exponent(s) for metanacrite sample.

Different models have been proposed to describe and draw the ac conduction model corresponding to metanacrite such as quantum mechanical tunneling (Q.M.T.) [23, 24], nonoverlapping small-polaron tunneling (N.S.P.T), overlapping large-polaron tunneling (O.L.P.T.), and the correlated barrier hopping (C.B.H.) [23-28]. 
According to Q.M.T. model, the ac conductivity originates from the tunneling of carriers between different valence states. In this case the expressions of the ac conductivity and frequency exponent are, respectively, given by the following equations [29]:

$$
\begin{aligned}
\sigma_{\mathrm{ac}}(\omega) & =\operatorname{Ce}^{2} a k T\left[N\left(E_{f}\right)\right]^{2} \omega R_{\omega}^{4}, \\
s & =1-\frac{4}{\ln \left(1 / \omega \tau_{0}\right)},
\end{aligned}
$$

where $[N(E f)]$ is the density of states at Fermi level, $R_{\omega}$ is the hopping length at frequency $\omega, \tau_{0}$ is the atomic vibration period, and $a$ is the localized radius. The last equation predicts that $s=0.8$ and is temperature independent. This implies that the Q.M.T. model is in disagreement with our results (see Figure 4).

In the case of the N.S.P.T model, it is usually associated with an increase in $s$ with temperature. Concerning the O.L.P.T model, the frequency exponent $s$ depends on both frequency and temperature and it drops to a minimum value with rising temperature and then increases as temperature rises. Finally, in the classical hopping model, the exponent $s$ is a constant value and is equal to unity [25].

All these models were deemed to be in disagreement with our results. Therefore, the experimental data will be discussed in the frame of the C.B.H. model. Thus, the conduction occurs via the hopping carriers over a potential barrier between two different valence states. The ac conductivity and frequency exponent expressions due to the C.B.H. model are given by the following equations:

$$
\begin{gathered}
\sigma_{\mathrm{ac}}(\omega)=\left(\frac{1}{24}\right) \pi^{3} \varepsilon^{\prime} N^{2} \varepsilon_{0} \omega R_{\omega}^{6}, \\
s=1-\left\{\frac{6 k T}{\left[W_{M}+k T \ln \left(1 / \omega \tau_{0}\right)\right]}\right\},
\end{gathered}
$$

where $\varepsilon_{0}$ is the free-space dielectric permittivity, $\varepsilon^{\prime}$ is the dielectric constant, and $W_{M}$ is the maximum barrier height. Equation (7) predicts that $s$ decreases with increasing temperature. Therefore the C.B.H. is the involved conduction mechanism for the investigated metanacrite synthetic sample [30, 31].

Concerning the ac conductivity of metanacrite, it is found to obey the universal Arrhenius power law [32]:

$$
\sigma_{\mathrm{ac}}=\sigma_{0} \exp \left(\frac{-E_{a(\mathrm{ac})}}{k_{B} T}\right),
$$

where $\sigma_{0}$ is the preexponential factor, $k_{B}$ is the Boltzmann constant, and $E_{a(\mathrm{ac})}$ is the activation energy that controls the jump of charge carriers from one site to another neighboring site. The $E_{a(\mathrm{ac})}$ values have been calculated at four fixed frequencies and are listed in Table 1.

Indeed, the activation energy varies between $0.24 \pm$ $0.01 \mathrm{eV}$ (at low frequencies) and $0.17 \pm 0.01 \mathrm{eV}$ (at high frequencies). These results are specific to the temperature range $773-873 \mathrm{~K}$. Thus, the increase of the applied frequency enhances the electronic jumps between the localized states.
TABLE 1: ac activation energies $E_{a(\text { ac })}$ for metanacrite sample.

\begin{tabular}{lcc}
\hline & Temperature range: $773 \rightarrow 873 \mathrm{~K}$ & \\
Frequency & $\begin{array}{c}E_{a(\mathrm{ac})}(\mathrm{eV}) \\
( \pm 0.01 \mathrm{eV})\end{array}$ \\
\hline $100 \mathrm{~Hz}$ & 0.24 \\
$1 \mathrm{MHz}$ & 0.21 \\
$5 \mathrm{MHz}$ & 0.20 \\
$10 \mathrm{MHz}$ & 0.17 \\
\hline
\end{tabular}

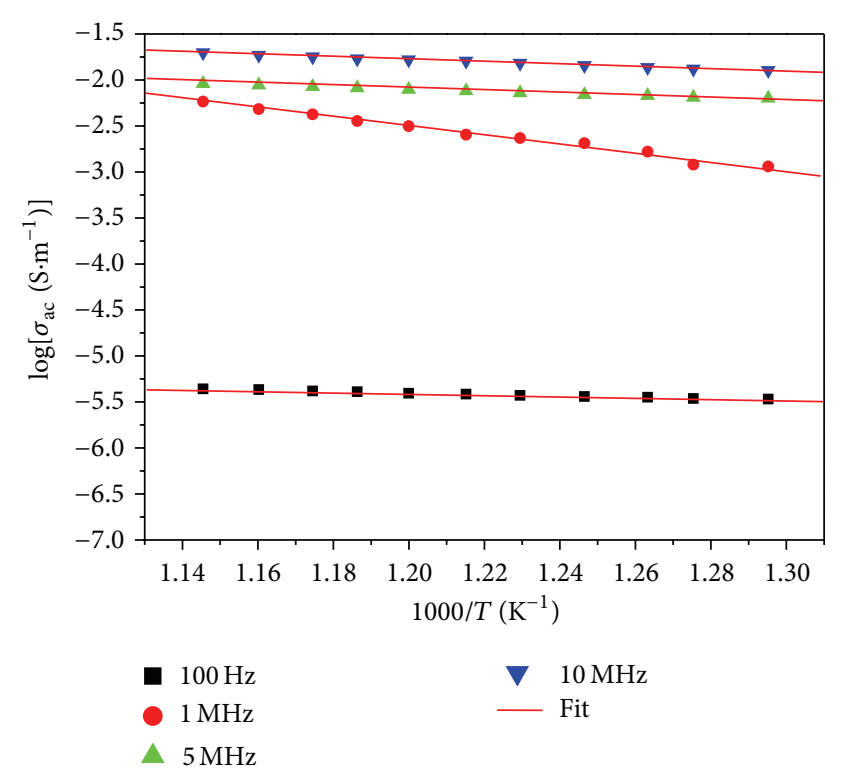

FIGURE 5: Evolution of the ac conductivity of metanacrite between $773 \mathrm{~K}$ and $873 \mathrm{~K}$ at $100 \mathrm{~Hz}, 1 \mathrm{MHz}, 5 \mathrm{MHz}$, and $10 \mathrm{MHz}$.

Consequently, the activation energy decreases with increasing frequency. Moreover, at high frequency, the ac activation energies are found to be lower than those found at low frequencies regions (see Figure 5). Therefore, at high frequencies the mobility of charge carriers over short distances needs lower energy than that necessary for mobility over longer distances at low frequencies.

The ac conductivity increases as a function of frequency at a fixed temperature $(773 \mathrm{~K})$ from $3.40 \cdot 10^{-6} \mathrm{~S} \cdot \mathrm{m}^{-1}$ at $f=$ $100 \mathrm{~Hz}$ to $1.27 \cdot 10^{-2} \mathrm{~S} \cdot \mathrm{m}^{-1}$ at $f=10 \mathrm{MHz}$ (Table 2). Besides the ac conductivity increases as a function of temperature at a fixed frequency $(f=10 \mathrm{MHz}$ ), it increases from 1.27 . $10^{-2} \mathrm{~S} \cdot \mathrm{m}^{-1}$ at $T=773 \mathrm{~K}$ to $1.98 \cdot 10^{-2} \mathrm{~S} \cdot \mathrm{m}^{-1}$ at $T=873 \mathrm{~K}$. The small values of the ac activation energy $E_{a(\mathrm{ac})}$ and the increase of ac conductivity $\sigma_{\mathrm{ac}}$ with the increase of frequency confirm the dominant hopping conduction mechanism.

The conductivity is thermally activated; therefore the electrical conduction follows a process in which the electron or hole hops from one localized site to another. The electron resides at one site; when it is thermally activated it migrates to another site. Moreover, we demonstrated in the first part of this paper that the defects constitute the active sites in the conduction process. Therefore, the electron or hole tends to associate with local defects, so the activation energy for 
TABLE 2: Variation of the ac conductivity as a function of temperature and frequency.

\begin{tabular}{lllll}
\hline \multirow{2}{*}{$\begin{array}{l}\text { Temperature } \\
\text { range }\end{array}$} & $f=100 \mathrm{~Hz}$ & $f=1 \mathrm{MHz}$ & $f=5 \mathrm{MHz}$ & $f=10 \mathrm{MHz}$ \\
\hline $773 \mathrm{~K}$ & $3.40 \cdot 10^{-6}$ & $1.14 \cdot 10^{-3}$ & $6.30 \cdot 10^{-3}$ & $1.27 \cdot 10^{-2}$ \\
$783 \mathrm{~K}$ & $3.45 \cdot 10^{-6}$ & $1.20 \cdot 10^{-3}$ & $6.45 \cdot 10^{-3}$ & $1.31 \cdot 10^{-2}$ \\
$793 \mathrm{~K}$ & $3.56 \cdot 10^{-6}$ & $1.66 \cdot 10^{-3}$ & $6.76 \cdot 10^{-3}$ & $1.37 \cdot 10^{-2}$ \\
$803 \mathrm{~K}$ & $3.62 \cdot 10^{-6}$ & $2.05 \cdot 10^{-3}$ & $6.91 \cdot 10^{-3}$ & $1.43 \cdot 10^{-2}$ \\
$813 \mathrm{~K}$ & $3.73 \cdot 10^{-6}$ & $2.33 \cdot 10^{-3}$ & $7.24 \cdot 10^{-3}$ & $1.52 \cdot 10^{-2}$ \\
$823 \mathrm{~K}$ & $3.84 \cdot 10^{-6}$ & $2.54 \cdot 10^{-3}$ & $7.59 \cdot 10^{-3}$ & $1.61 \cdot 10^{-2}$ \\
$833 \mathrm{~K}$ & $3.92 \cdot 10^{-6}$ & $3.14 \cdot 10^{-3}$ & $7.87 \cdot 10^{-3}$ & $1.66 \cdot 10^{-2}$ \\
$843 \mathrm{~K}$ & $4.08 \cdot 10^{-6}$ & $3.57 \cdot 10^{-3}$ & $8.17 \cdot 10^{-3}$ & $1.70 \cdot 10^{-2}$ \\
$853 \mathrm{~K}$ & $4.16 \cdot 10^{-6}$ & $4.23 \cdot 10^{-3}$ & $8.45 \cdot 10^{-3}$ & $1.78 \cdot 10^{-2}$ \\
$863 \mathrm{~K}$ & $4.30 \cdot 10^{-6}$ & $4.81 \cdot 10^{-3}$ & $8.79 \cdot 10^{-3}$ & $1.86 \cdot 10^{-2}$ \\
$873 \mathrm{~K}$ & $4.38 \cdot 10^{-6}$ & $5.83 \cdot 10^{-3}$ & $9.12 \cdot 10^{-3}$ & $1.98 \cdot 10^{-2}$ \\
\hline
\end{tabular}

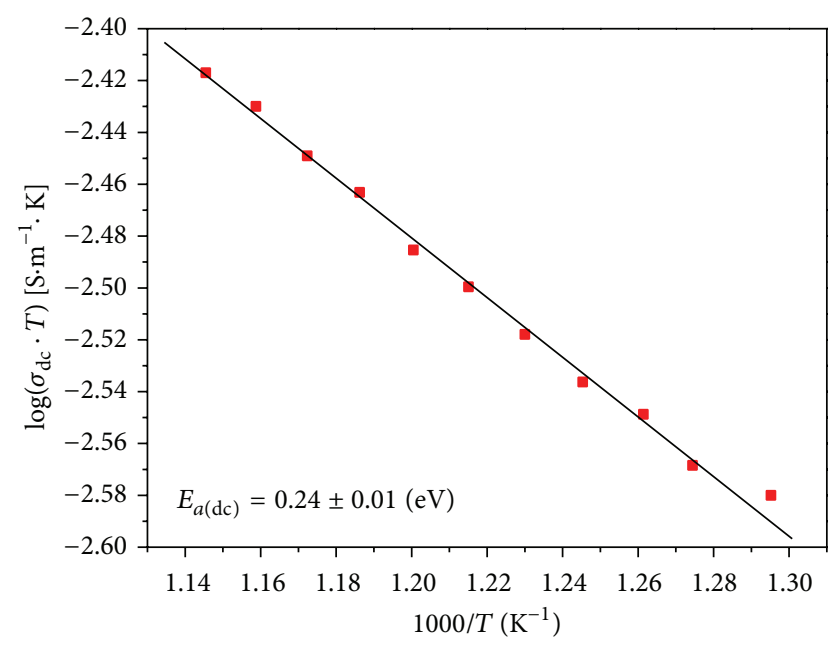

FIGURE 6: Evolution of the dc conductivity of metanacrite between $773 \mathrm{~K}$ and $873 \mathrm{~K}$.

charge transport may also include the energy of freeing the hole from its position next to the defect [33]. Otherwise, the electronic conduction takes place by hopping between two charge-defect states over the barrier separating them.

As mentioned above, the ac conductivity increases with increasing both temperature and frequency. Simultaneously, the $\mathrm{dc}$ conductivity increases with increasing temperature (Figure 6).

Indeed, the dc conductivity $\left(\sigma_{\mathrm{dc}}\right)$ fits the well-known Arrhenius relation [32]. We found $E_{a(\mathrm{dc})}=0.24 \pm 0.01 \mathrm{eV}$ (see Figure 6):

$$
\sigma_{\mathrm{dc}}=\frac{\sigma_{0}}{T} \exp \left(\frac{-E_{a(\mathrm{dc})}}{k_{B} T}\right),
$$

where $\sigma_{0}$ is the preexponential factor, $E_{a(\mathrm{dc})}$ is the activation energy, and $k_{B}$ is the Boltzmann constant.

As a consequence of the increased dc conductivity with temperature for small activation energies we conclude that the amorphous metanacrite sample behaves like a semiconductor material. To add a more comprehensive picture about the transport mechanism of the present synthetic sample, dielectric investigations were carried out. Results are reported in Figure 7.

The complex permittivity, the dielectric constant $\varepsilon^{\prime}(\omega)$, and the dielectric loss $\varepsilon^{\prime \prime}(\omega)$ are determined according to the following expressions [34]:

$$
\begin{gathered}
\varepsilon^{*}(\omega)=\varepsilon^{\prime}(\omega)-j \varepsilon^{\prime \prime}(\omega), \\
\varepsilon^{\prime}=\frac{-Z^{\prime \prime}}{C_{0}\left(Z^{\prime 2}+Z^{\prime \prime 2}\right) \omega}, \\
\varepsilon^{\prime \prime}=\frac{Z^{\prime}}{C_{0}\left(Z^{\prime 2}+Z^{\prime \prime 2}\right) \omega},
\end{gathered}
$$

where $Z^{\prime}$ is the real part of the electric impedance, $Z^{\prime \prime}$ is the imaginary part of the electric impedance, $j^{2}=-1, C_{0}=\varepsilon_{0} S / d$ is the capacitance of the empty cell, $\omega$ is the angular frequency, $\varepsilon_{0}$ is the dielectric permittivity of free space $(8,85418782 \times$ $\left.10^{-12} \mathrm{~F} \cdot \mathrm{m}^{-1}\right), S$ is the electrode surface, and $d$ is the distance between the two plane electrodes.

Upon heat treatment of metanacrite from room temperature to $873 \mathrm{~K}$, the disorder degree and the number of defects rise more significantly which influences the dielectric permittivity considerably.

From Figure 7(a), it is found that heating of metanacrite undergoes a gradual decrease in the dielectric constant. The observed dielectric dispersion at low frequencies may be associated with the thermally activated conduction of mobile current carriers and with the increase of disorder degree and defects density in the sample. Simultaneously, we mark a low frequency dispersion and increase of the dielectric loss $\left(\varepsilon^{\prime \prime}\right)$ in the temperature domain ranging from $773 \mathrm{~K}$ up to $873 \mathrm{~K}$ (Figure 7(b)). Indeed, according to the structural analysis, metanacrite sample is characterized by a significant decrease of grain dimensions caused by the destruction and decomposition of the layered nacrite material. Therefore, metanacrite exhibits defects that liberated a small distance movement. So, the charge carriers are assumed to migrate easily. This allows increasing the polarization with temperature.

However, at high frequencies, the dielectric constant remains invariant with temperature (Figure $7(\mathrm{a})$ ); the dielectric loss drops and becomes almost temperature independent for $f>10^{3} \mathrm{~Hz}$ (Figure 7(b)); this may be due to the fact that, in the high frequency range, the charge carriers cannot follow the electric field.

The behavior of $\varepsilon^{\prime \prime}$ as a function of both frequency and temperature can be analyzed according to Giuntini equation [35]:

$$
\varepsilon^{\prime \prime}=\left(\varepsilon_{s}-\varepsilon_{\infty}\right) 2 \pi^{2} N\left(\frac{n e^{2}}{\varepsilon_{s}}\right)^{3} k T \omega^{m} \tau^{m} W_{M}^{-4}
$$

where $\varepsilon^{\prime \prime}$ should follow a power law with frequency:

$$
\begin{gathered}
\varepsilon^{\prime \prime}=B \omega^{m}, \\
m=-\frac{4 k T}{W_{M}},
\end{gathered}
$$



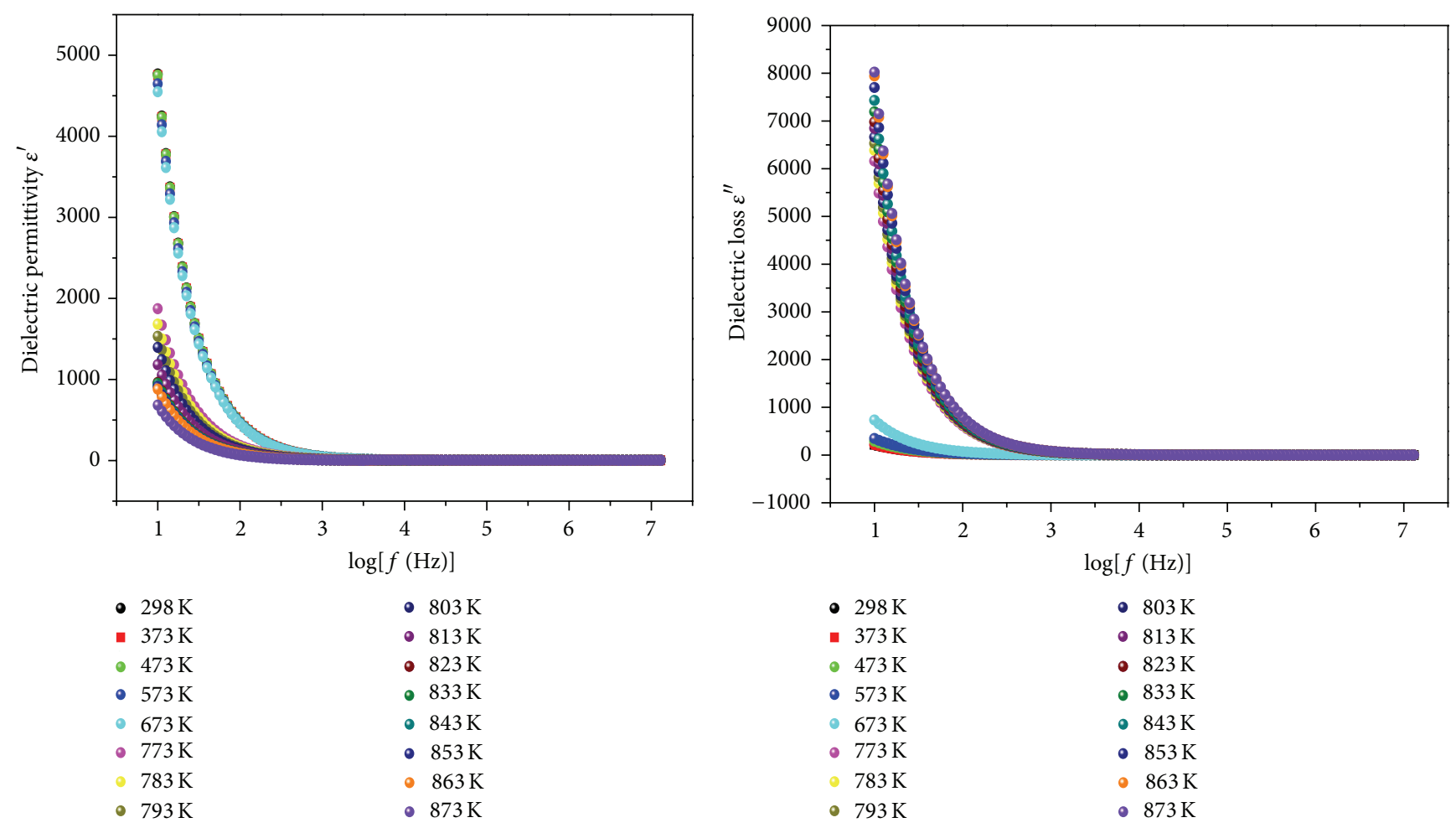

(a)

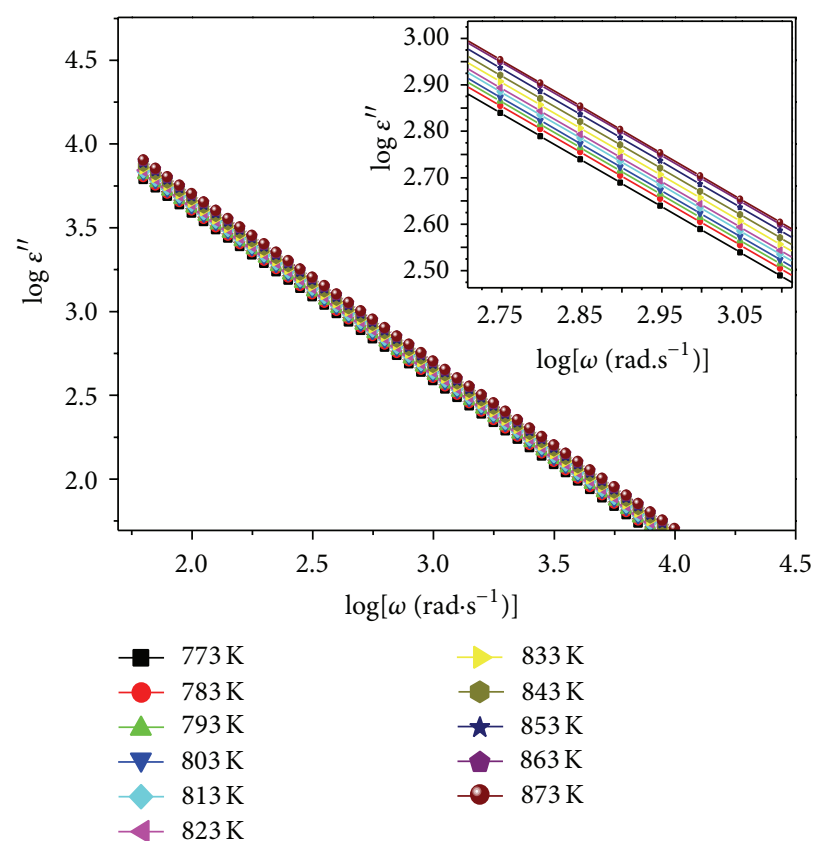

(b)

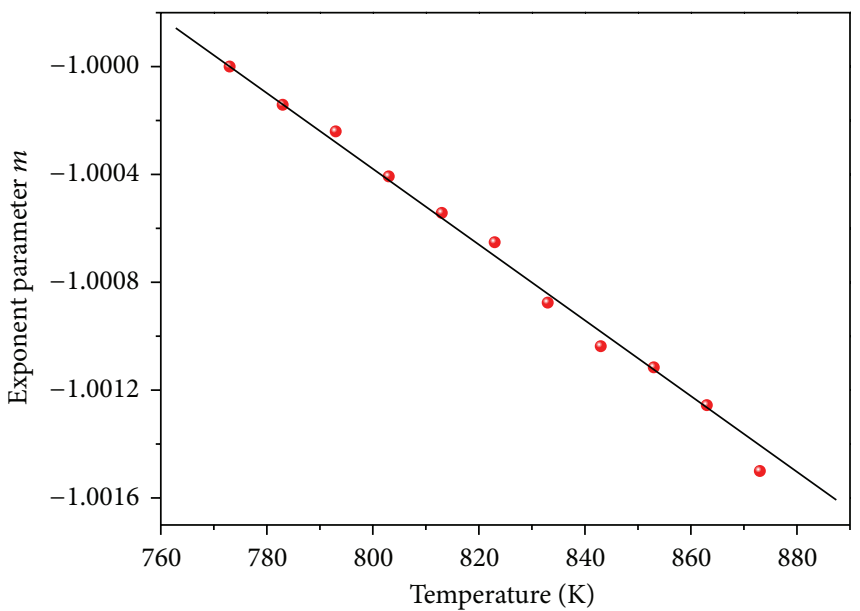

(c)

(d)

FIGURE 7: (a) Variation of real part $\left(\varepsilon^{\prime}\right)$ of dielectric permittivity with frequency at temperature range from 298 to $873 \mathrm{~K}$ for metanacrite. (b) Variation of imaginary part $\left(\varepsilon^{\prime \prime}\right)$ of dielectric permittivity with frequency at temperature range from 298 to $873 \mathrm{~K}$ for metanacrite. Frequency dependence of imaginary $\left(\varepsilon^{\prime \prime}\right)$ part of dielectric permittivity in the (773-873 K) temperature range on a log-log scale. (d) Temperature dependence of frequency exponent, $m$, for metanacrite sample. 
where $W_{M}$ is the maximum barrier height, $\varepsilon_{s}$ is the static dielectric constant, $\varepsilon_{\infty}$ is the dielectric constant at infinite frequency, $B$ is a constant depending on temperature, $\tau$ is the relaxation time for electrons to hop over a barrier, and $k$ is Boltzmann's constant.

The variation of $\varepsilon^{\prime \prime}$ with frequency on double logarithmic scale at different temperatures for metanacrite presents a series of straight lines with different slopes (Figure $7(\mathrm{c})$ ).

The power, $m$, represents the value of the slope corresponding to each temperature. $m$ decreases with increasing temperature showing a linear behavior which is observed in Figure $7(\mathrm{~d})$; the maximum barrier height $W_{M}$ was found to be $0.13 \mathrm{eV}$.

\section{Conclusions}

The structural and electrical properties of metanacrite synthesized from Tunisian nacrite raw clay were investigated. The amorphous character of metanacrite was identified using XRD, IR, TEM, and EDXS analysis. Results of the electrochemical impedance spectroscopy show that the sample behaves like a semiconductor material. On the other hand, an enhancement of the electrical conductivity is clear with increase in temperature and frequency. Application of the C.B.H. model reveals that the electronic conduction mechanism is governed by hopping between two charge-defect states over a barrier height $W_{M}$ around $0.13 \mathrm{eV}$. The electri$\mathrm{cal} /$ dielectric properties agree very well with the structural analysis.

The present work gives possible valorization of Tunisian metanacrite as an interesting precursor to produce a new class of cementitious materials possessing good electrical properties. Further studies are in progress to point up the use of this amorphous semiconductor material in diverse electronic applications with a cost-benefit focus.

\section{Conflict of Interests}

The authors declare that there is no conflict of interests regarding the publication of this paper.

\section{Acknowledgment}

The authors are thankfully grateful to Professor Mosbah Amlouk (Unité de Physique des Dispositifs à Semiconducteurs, Tunis El Manar University) for helpful discussion and corrections.

\section{References}

[1] M. Castellano, A. Turturro, P. Riani et al., "Bulk and surface properties of commercial kaolins," Applied Clay Science, vol. 48, no. 3, pp. 446-454, 2010.

[2] B. K. Benazzouz and A. Zaoui, "Phase diagram of kaolinite from Molecular Dynamics calculations," Physica B: Condensed Matter, vol. 407, no. 13, pp. 2462-2470, 2012.

[3] H. H. Murray, "Kaolin applications," in Applied Clay Mineralogy. Occurrences, Processing and Application of Kaolins, Bentonites,
Palygorskite-Sepiolite and Common Clays, H. H. Murray, Ed., pp. 85-109, Elsevier, Amsterdam, The Netherlands, 2007.

[4] M. I. Carretero and M. Pozo, "Clay and non-clay minerals in the pharmaceutical and cosmetic industries Part II. Active ingredients," Applied Clay Science, vol. 47, no. 3-4, pp. 171-181, 2010.

[5] S. W. Bailey, "Polymorphism of the kaolin minerals," American Mineralogist, vol. 48, pp. 1197-1209, 1963.

[6] K. Leluk, K. Orzechowski, K. Jerie, A. Baranowski, T. SŁonka, and J. GŁowiński, "Dielectric permittivity of kaolinite heated to high temperatures," Journal of Physics and Chemistry of Solids, vol. 71, no. 5, pp. 827-831, 2010.

[7] G. D. Anthony and P. D. Garn, "Kinetics of kaolinite dehydroxylation," Journal of the American Ceramic Society, vol. 57, no. 3, pp. 132-135, 1974.

[8] J. McManus, S. E. Ashbrook, K. J. D. MacKenzie, and S. Wimperis, " ${ }^{27} \mathrm{Al}$ multiple-quantum MAS and ${ }^{27} \mathrm{Al}^{1} \mathrm{H}$ CPMAS NMR study of amorphous aluminosilicates," Journal of NonCrystalline Solids, vol. 282, no. 2-3, pp. 278-290, 2001.

[9] B. Sabir, S. Wild, and J. Bai, "Metakaolin and calcined clays as pozzolans for concrete: a review," Cement and Concrete Composites, vol. 23, no. 6, pp. 441-454, 2001.

[10] J. R. Memon, K. R. Hallam, M. I. Bhanger, A. El-Turki, and G. C. Allen, "Evaluation of sorption of uranium onto metakaolin using X-ray photoelectron and Raman spectroscopies," Analytica Chimica Acta, vol. 631, no. 1, pp. 69-73, 2009.

[11] S. Wild, J. M. Khatib, and A. Jones, "Relative strength, pozzolanic activity and cement hydration in superplasticised metakaolin concrete," Cement and Concrete Research, vol. 26, no. 10, pp. 1537-1544, 1996.

[12] N. J. Coleman and C. L. Page, "Aspects of the pore solution chemistry of hydrated cement pastes containing metakaolin," Cement and Concrete Research, vol. 27, no. 1, pp. 147-154, 1997.

[13] M. Frías and J. Cabrera, "Pore size distribution and degree of hydration of metakaolin-cement pastes," Cement and Concrete Research, vol. 30, no. 4, pp. 561-569, 2000.

[14] S. N. Patil, A. K. Gupta, and S. S. Deshpande, "Metakaolinpozzolanic material for cement in high strength concrete," in Proceedings of the 2nd International Conference on Emerging Trends in Engineering (SICETE '13), pp. 46-49, 2013.

[15] H. Douiri, S. Louati, S. Baklouti, M. Arous, and Z. Fakhfakh, "Structural, thermal and dielectric properties of phosphoric acid-based geopolymers with different amounts of $\mathrm{H}_{3} \mathrm{PO}_{4}$," Materials Letters, vol. 116, pp. 9-12, 2014.

[16] A. B. H. Amara, J. B. Brahim, N. B. Ayed, and H. B. Rhaiem, "Présence de nacrite sur d'anciens gisements de $\mathrm{Pb}-\mathrm{Zn}$ du nord Tunisien," Clay Minerals, vol. 31, pp. 127-130, 1996.

[17] A. Ben Haj Amara, J. Ben Brahim, A. Plançon, H. Ben Rhaiem, and G. Besson, "Étude Structurale d'une Nacrite Tunisienne," Journal of Applied Crystallography, vol. 30, no. 3, pp. 338-344, 1997.

[18] A. Ben Haj Amara, "X-ray diffraction, infrared and TGA/DTG analysis of hydrated nacrite," Clay Minerals, vol. 32, no. 3, pp. 463-470, 1997.

[19] A. B. H. Amara, A. Plançon, J. Ben Brahim, and H. Ben Rhaiem, "XRD study of the stacking mode in natural and hydrated nacrite," Materials Science Forum, vol. 278-281, no. 2, pp. 809813, 1998.

[20] A. Ben Haj Amara, J. Ben Brahim, A. Plançon, and H. Ben Rhaiem, "Étude par diffraction X des modes d'empilement de la nacrite hydratée et deshydratée," Journal of Applied Crystallography, vol. 31, no. 5, pp. 654-662, 1998. 
[21] N. Jaafar, H. Ben Rhaiem, and A. B. H. Amara, "Synthesis, characterization and applications of a new nanohybrid composite: Nacrite/ $\mathrm{MgCl}_{2} \cdot 6 \mathrm{H}_{2} \mathrm{O}$ /ethanol," in Proceedings of the International Conference on Composite Materials \& Renewable Energy Applications (ICCMREA '14), pp. 1-6, Sousse, Tunisia, January 2014.

[22] A. K. Jonscher, "The "universal" dielectric response," Nature, vol. 267, no. 5613, pp. 673-679, 1977.

[23] I. G. Austin and N. F. Mott, "Polarons in crystalline and noncrystalline materials," Advances in Physics, vol. 18, no. 71, pp. 41102, 1969.

[24] M. Pollak, "On the frequency dependence of conductivity in amorphous solids," Philosophical Magazine, vol. 23, no. 183, pp. 519-542, 1971.

[25] G. E. Pike, "ac conductivity of scandium oxide and a new hopping model for conductivity," Physical Review B, vol. 6, no. 4, pp. 1572-1580, 1972.

[26] S. R. Elliott, "A theory of a.c. conduction in chalcogenide glasses," Philosophical Magazine, vol. 36, no. 6, pp. 1291-1304, 1977.

[27] B. E. Springett, "ac Conductivity of $4.5 \mathrm{TiO}_{2-x} \cdot 2 \mathrm{P}_{2} \mathrm{O}_{5}$," Journal of Non-Crystalline Solids, vol. 15, no. 2, pp. 179-190, 1974.

[28] S. R. Elliott, "A.c. conduction in amorphous chalcogenide and pnictide semiconductors," Advances in Physics, vol. 36, no. 2, pp. 135-218, 1987.

[29] M. I. Mohammed, K. Abd-Allah, and M. Y. Hassaan, "The conduction mechanism and dielectric behavior of sodium borate glasses containing $\mathrm{Fe}$ and Bi ions," Egyptian Journal of Solids, vol. 27, no. 2, pp. 299-308, 2004.

[30] J. C. Giuntini, B. Deroide, P. Belougne, and J. V. Zanchetta, "Numerical approach of the correlated barrier hopping model," Solid State Communications, vol. 62, no. 11, pp. 739-742, 1987.

[31] Y. Bensimon, J. C. Giuntini, P. Belougne, B. Deroide, and J. V. Zanchetta, "An example of A.C. conduction by correlated barrier hopping in amorphous molybdenum sulphides," Solid State Communications, vol. 68, no. 2, pp. 189-192, 1988.

[32] R. E. Hummel, Electronic Properties of Materials, Springer, New York, NY, USA, 1993.

[33] H. Nefzi, F. Sediri, H. Hamzaoui, and N. Gharbi, "Dielectric properties and electrical conductivity of the hybrid organicinorganic polyvanadates $\left(\mathrm{H}_{3} \mathrm{~N}\left(\mathrm{CH}_{2}\right)_{4} \mathrm{NH}_{3}\right)\left[\mathrm{V}_{6} \mathrm{O}_{14}\right]$," Journal of Solid State Chemistry, vol. 190, pp. 150-156, 2012.

[34] J. R. Macdonald, Ed., Impedance Spectroscopy-Emphasizing, Solid Materials and Systems, Wiley-Interscience, New York, NY, USA, 1987.

[35] J. C. Giuntini, J. V. Zanchetta, D. Jullien, R. Eholie, and P. Houenou, "Temperature dependence of dielectric losses in chalcogenide glasses," Journal of Non-Crystalline Solids, vol. 45, no. 1, pp. 57-62, 1981. 

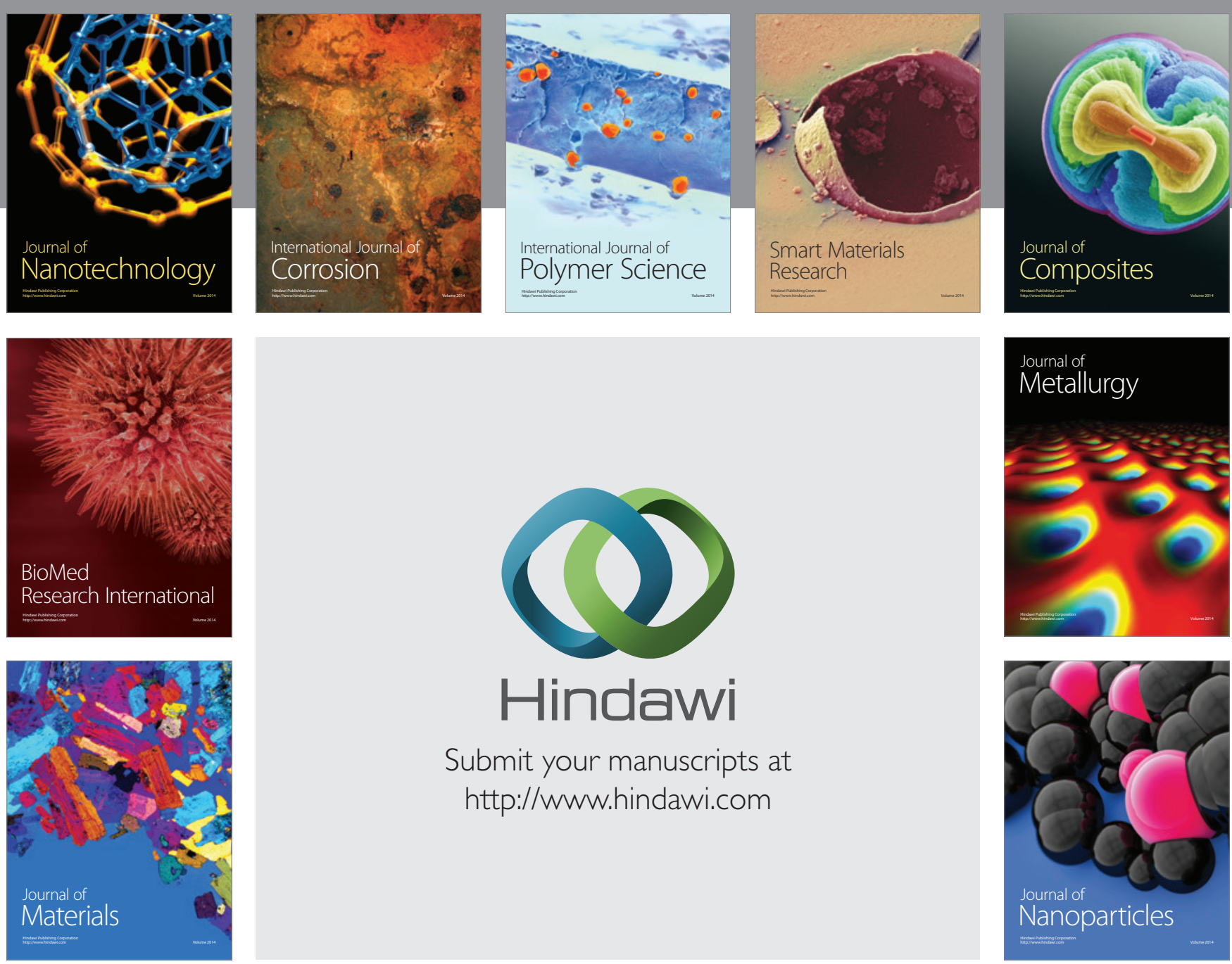

Submit your manuscripts at http://www.hindawi.com
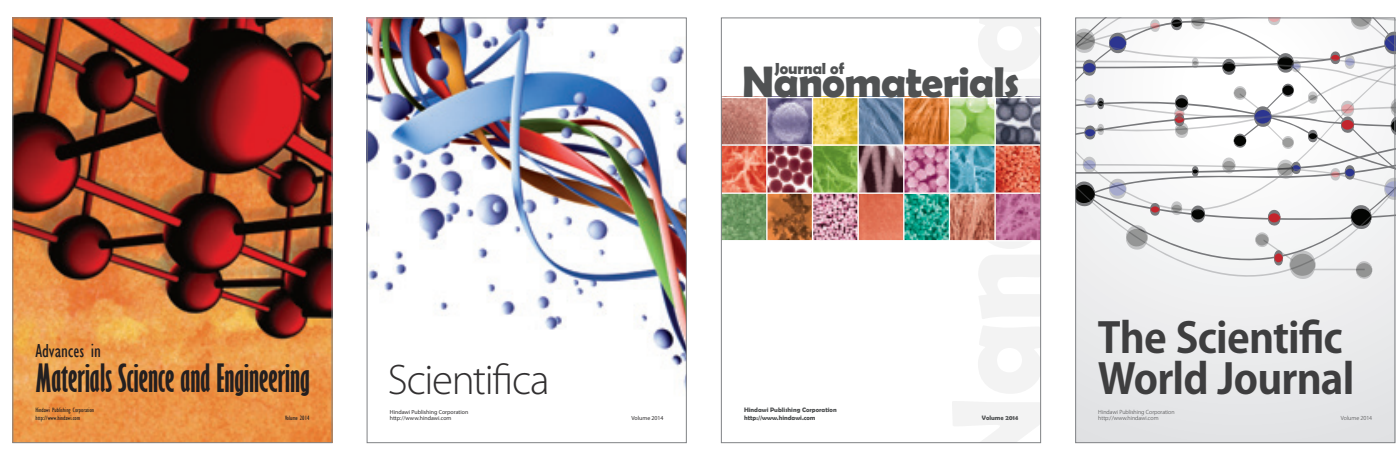

\section{The Scientific World Journal}
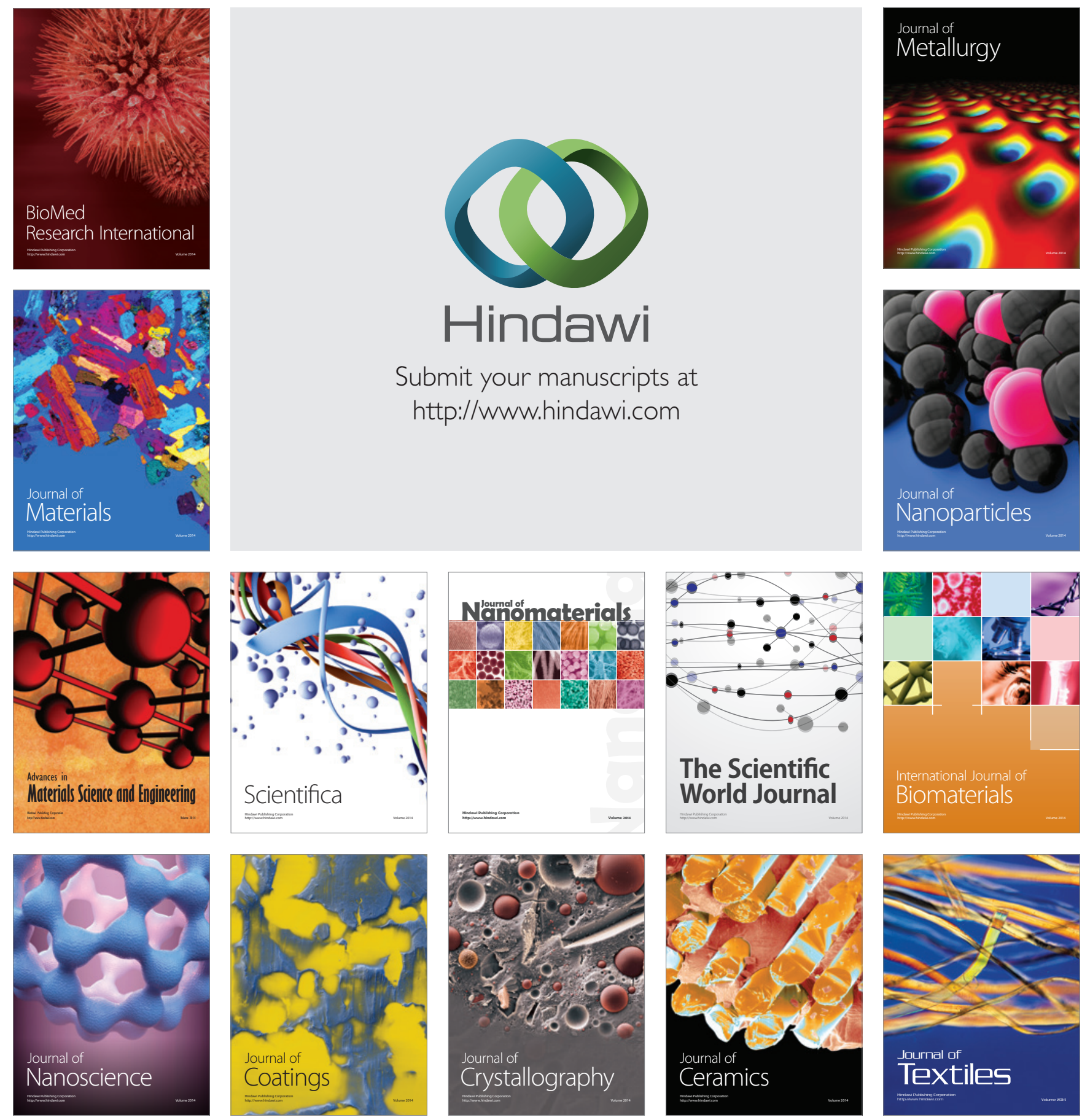